\title{
BMJ Open Predictors of public support for nutrition-focused policy, systems and environmental change strategies in Los Angeles County, 2013
}

\author{
Brenda Robles, , ${ }^{1,2}$ Tony Kuo 1,3,4
}

To cite: Robles B, Kuo T. Predictors of public support for nutrition-focused policy, systems and environmental change strategies in LoS Angeles County, 2013. BMJ Open 2017;7:e012654. doi:10.1136/bmjopen-2016012654

- Prepublication history for this paper is available online. To view these files please visit the journal online (http://dx.doi.org/10.1136/ bmjopen-2016-012654).

Received 17 May 2016 Revised 8 August 2016 Accepted 28 September 2016

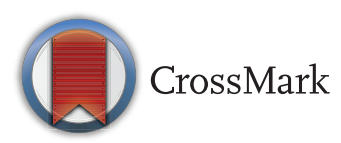

For numbered affiliations see end of article.

Correspondence to Brenda Robles; brrobles@ph.lacounty.gov

\section{ABSTRACT}

Background: Since 2010, federal and local agencies have invested broadly in a variety of nutrition-focused policy, systems and environmental change (PSE) initiatives in Los Angeles County (LAC). To date, little is known about whether the public supports such efforts. We address this gap in the literature by examining predictors of support for a variety of PSEs.

Methods: Voters residing in LAC $(n=1007)$ were randomly selected to participate in a cross-sectional telephone survey commissioned by the LAC Department of Public Health. The survey asked questions about attitudes towards the obesity epidemic, nutrition knowledge and behaviours, public opinions about changing business practices/ government policies related to nutrition, and sociodemographics. A factor analysis informed outcome variable selection (ie, type of PSEs). Multivariable regression analyses were performed to examine predictors of public support. Predictors in the regression models included (primary regressor) community economic hardship; (control variables) political affiliation, sex, age, race and income; and (independent variables) perceptions about obesity, perceived health and weight status, frequency reading nutrition labels, ease of finding healthy and unhealthy foods, and food consumption behaviours (ie, fruit and vegetables, non-diet soda, fast-food and sit-down restaurant meals).

Results: 3 types of PSE outcome variables were identified: promotional/incentivising, limiting/restrictive and business practices. Community economic hardship was not found to be a significant predictor of public support for any of the 3 PSE types. However, Republican party affiliation, being female and perceiving obesity as a serious health problem were. Conclusions: These findings have implications for public health practice and community planning in local health jurisdictions.

\section{INTRODUCTION}

Although factors such as unhealthy eating behaviors and personal choice have been attributed to obesity and chronic disease risk

\section{Strengths and limitations of this study}

- This study is the first to describe and compare public support of recent nutrition-focused policy, systems and environmental change efforts in an urban jurisdiction by community economic hardship.

- The results shed critical insights on public support for recent nutrition-focused policies/ practices that aim to reduce obesity in the community.

- Findings from the present study have policy implications for present and forthcoming policy, systems, and environmental change efforts for obesity prevention in the USA.

- Limitations of the present study include social desirability bias that may have resulted in respondents over-reporting level of policy support and self-selection bias due to the nature of crosssectional surveys.

in the population, ${ }^{1-3}$ public health authorities have increasingly come to recognize the benefits of addressing other determinants of health such as the physical, the social, and the food environment (ie, elements that often negate personal choice) as a way to reduce obesity-related disparities in the community. ${ }^{45}$ Socio-economically disadvantaged individuals, for example, are more likely to live in neighborhoods that lack access to healthy eating supports, including supermarkets and affordable produce. ${ }^{6}$ Such socioecological barriers to healthy eating have been implicated as being contributors to poor dietary behaviors ${ }^{78}$ and to differential health outcomes in underserved communities. ${ }^{6} 9$

Guided in part by the Socio-Ecological Model which highlights the interactions between individuals and their physical and sociocultural environments, ${ }^{10}$ the Los Angeles County (LAC) Department of Public Health (DPH) has sought to address underlying socio-ecological barriers to healthy 
eating for its 10 million residents through recent implementation of policy, systems and environmental (PSE) change strategies in nutrition. ${ }^{11}{ }^{12}$ While local in its focus, these efforts were part of larger federal initiatives to combat obesity between 2010 and $2014 .^{13} 14$

There is a growing recognition that a better understanding of public support and how public health strategies such as PSEs are perceived in the community could inform their implementation in target populations. For instance, examining and documenting level of public support of different types of PSE strategies may help policymakers/funders prioritise which PSE interventions to implement in a community or help local health departments identify target audiences that may be most receptive to such interventions. Gauging public opinions, in particular, has been cited as an important step for facilitating the early dialogue and downstream success of PSE interventions. ${ }^{15}$ An important question to ask is, "Do communities targeted by nutrition-focused PSE strategies actually support them in their communities?" From a policy and practice standpoint, it is also important to understand how public support might vary by community, especially by economic hardship (EH) levels. There is emerging literature to suggest that higher levels of community $\mathrm{EH}$ is associated with higher obesity prevalence. ${ }^{16-18}$

While some studies have examined public support of policies promoting healthy eating/nutrition, they have focused primarily on workplace issues, ${ }^{19}$ childhood obesity ${ }^{20}$ or on international obesity prevention efforts. ${ }^{21-25}$ To date, few studies have examined perceptions pertaining to food or obesity prevention PSE practices or interventions in the USA. $^{26-28}$ To the best of our knowledge, no studies have examined predictors of public support of recent nutrition-focused PSE efforts in local jurisdictions.

The present analysis seeks to shed light on this gap in the literature. The analysis compared potential predictors of public support for nutrition-focused PSEs among a representative sample of LAC residents. The main predictor of interest was community EH status, which comprised three levels: 'low', 'intermediate' or 'high'. Given residents from high EH communities are more likely to experience disparities in access to healthy eating resources ${ }^{29}$ we expected residents from these communities to express a high level of PSE support. Other potential predictors examined were political affiliation, sociodemographics (ie, sex, age, race and income), perceptions about obesity, perceived health and weight status, frequency reading nutrition labels, ease of finding healthy and unhealthy foods, and food consumption behaviours (ie, fruit and vegetables, non-diet soda, fast-food and sit-down restaurant meals).

\section{METHODS}

The LAC Food and Nutrition Field Survey

A cross-sectional telephone survey conducted by Field Research Corporation, a California-based survey firm, was administered to a simple random sample of voters selected from the County of Los Angeles Registrar's voter registry (list) in October 2013. To be eligible, respondents had to: (1) be the person whose name was selected from the list, (2) confirm his/her accuracy of living in the jurisdiction; and (3) speak English or Spanish. Of the 1007 who completed interviews, 661 $(66 \%)$ originated from a cell phone listing and 346 $(34 \%)$ originated from a landline or other non-cellular phone listing. To obtain an accurate and reliable snapshot of the county population, the final sample included a main countywide sample of LAC voters $(n=700)$, along with two additional augmented samples of voters residing in the City of Los Angeles ( $n=26)$ and in South Los Angeles $(n=281)$. Respondents residing in South Los Angeles zip codes (ie, low-income, high priority areas) were oversampled for strategic planning purposes and because they have been heavily targeted by recent PSE interventions (table 1).

\section{Survey instrument}

The seven-page, 35-item questionnaire (administered in English or Spanish) was developed by DPH in collaboration with Field Research Corporation. All questions were closed-ended, with voters asked to choose their answers from a short list of possible answer alternatives or by providing a numeric response. Survey measures included attitudes towards obesity epidemic, nutrition knowledge and behaviours, public opinions about PSE strategies seeking to change business practices and to promote healthy eating, and sociodemographics. When feasible, questions were adapted from previously validated items used in DPH or Field Research surveys; however, due to lack of previous studies on this topic, several questions (eg, beliefs of factors contributing to obesity) were developed specifically for the survey.

\section{Measures for descriptive and multivariable analyses Policy support}

Policy support was measured using a series of questions adapted from prior local obesity-related public opinion surveys conducted by Field Research in the region. ${ }^{30-33}$ First, respondents were asked, "How important is it for food and beverage companies to do this: (1) change the ingredients in their products to reduce their calories; (2) change the ingredients in their products to reduce their sodium or salt content; and (3) stop advertising unhealthy products, like fast food and sodas, on TV shows that kids watch frequently?" Response options included "very important", "somewhat important", "not too important", "not at all important" or "don't know/ refuse". Second, respondents were asked to indicate the degree to which they favour the following actions: (1) limiting the container sizes in which sodas and other sugary drinks can be sold in restaurants, snack bars, movie theatres and sports arenas to no more than 16 ounces; (2) providing incentives and enact policies to attract more farmers markets to produce stands selling fresh fruits and vegetables in low-income 
Table 1 Number and type of nutrition-related PSE change investments for obesity prevention in South Los Angeles, 2010$2014^{*}$

\begin{tabular}{|c|c|c|c|c|}
\hline \multirow[b]{2}{*}{ Goal } & \multirow[b]{2}{*}{ Targeted setting } & \multicolumn{3}{|c|}{$\begin{array}{l}\text { Number and type of PSE change } \\
\text { activity }\end{array}$} \\
\hline & & Policy† & Systems $¥$ & Environment§ \\
\hline \multirow{3}{*}{ Increase access to healthy foods and beverages } & Schools & 6 & 3 & 3 \\
\hline & Child or adult care settings & 1 & 1 & 1 \\
\hline & Healthcare & 3 & 1 & 1 \\
\hline \multirow[t]{4}{*}{ Increase access to opportunities for physical activity } & Neighbourhoods & 8 & 6 & 10 \\
\hline & Schools & 3 & 2 & 0 \\
\hline & Child or adult care settings & 1 & 1 & 1 \\
\hline & Healthcare & 3 & 1 & 1 \\
\hline \multicolumn{5}{|c|}{$\begin{array}{l}\text { *A substudy was conducted between September and December } 2014 \text { by DPH to understand obesity prevention efforts within Los Angeles } \\
\text { County between } 2010 \text { and } 2014 \text {; PSE efforts were inventoried to build a database describing the major PSE programmes and initiatives by } \\
\text { funding stream, geography and major activities to inform strategic planning efforts in the region. In total, } 51 \text { interviews were completed with } \\
\text { academic agencies, CBOs, community clinic/health services providers, faith-based organisations, funders, government agencies, non-profits } \\
\text { and schools. } \\
\text { tPolicy changes include strategies such as adoption of shared use agreements to facilitate access to physical activity and healthcare } \\
\text { resources, nutrition standards for institutional food service settings (eg, school or county agency cafeterias), or community plans to guide } \\
\text { health promotion of urban growth and development. } \\
\text { ¥Systems changes involve modifications to practices such as development of interagency networks and partnerships, local capacity building } \\
\text { to conduct community needs assessments, or the implementation of referral systems to community-based obesity prevention resources. } \\
\text { §Environmental changes are physical modifications such as increased lighting and safety standards in public parks, establishment or } \\
\text { expansion of farmers markets or healthy food offerings, or the construction of walking and biking infrastructure (eg, trails, bike lanes, cross } \\
\text { walks). } \\
\text { CBO, community-based organisation; DPH, The Los Angeles County Department of Public Health; PSE, policy, systems and environmental } \\
\text { change strategy interventions. }\end{array}$} \\
\hline
\end{tabular}

neighbourhoods; (3) increasing the availability of fresh drinking water at local parks, schools and other public areas; (4) providing incentives and enact policies to attract more supermarkets selling fresh fruits and vegetables in low-income neighbourhoods; (5) prohibiting supermarkets from selling unhealthy food items, like candy products, in their check-out aisle; (6) setting a limit on the number of fast-food restaurants that a community can have; (7) providing local grocery and convenience stores with tax credits and other incentives to provide more healthy food choices, like fresh fruits and vegetables, and to reduce the number of unhealthy foods and snacks they sell; (8) strengthening school nutrition standards to limit the types of unhealthy foods and sugary drinks sold in schools; and (9) reducing access to unhealthy snacks and sugary drinks in vending machines in public buildings and worksites. Response options included "favour strongly", "favour somewhat", "oppose somewhat", "oppose strongly," and "don't know/refuse".

In descriptive analyses, responses to the series of PSE support questions were dichotomized as 'favors strongly' if respondents answered "favor strongly" and 'does not favor strongly' if respondents answered "favor somewhat," "oppose somewhat," or "oppose strongly." Similarly, responses were dichotomized as "finds very important' if respondents answered "very important" and 'does not find very important' if respondents answered "somewhat important," "not too important," or "not at all important."
For multivariable regression modelling, a factor analysis informed three index (outcome) variables of policy support for PSE efforts. These variables (continuous) are an average of respondent responses, based on a fourpoint Likert scale, to the aforementioned series of PSE public support questions. The first outcome variablepromotional or incentivising policies and practicesincluded questions pertaining to respondent level of support for: (1) attracting more supermarkets selling fresh fruits and vegetables in low-income neighbourhoods; (2) attracting more farmers markets and produce stands selling fresh fruits and vegetables in low-income neighbourhoods; (3) increasing the availability of fresh drinking water in public areas; and (4) providing local grocery and convenience stores with tax credits/other incentives to provide more healthy food choices. The second outcome variable-limiting and restrictive policies and practices-included questions relating to respondent level of support for: (1) limiting the container sizes of sodas and other sugary drinks sold; (2) prohibiting supermarkets from selling unhealthy food items; (3) limiting the number of fast-food restaurants that a community can have; (4) strengthening school nutrition standards to limit the types of unhealthy foods and sugary drinks sold; and (5) reducing access to unhealthy snacks and sugary drinks in vending machines in public buildings and work sites. The third index outcome variable-public opinions about the importance of changing business practices-included questions 
on respondents' perceived level of importance that food and beverage companies: (1) change the ingredients in their products to reduce their calories; (2) change the ingredients in their products to reduce their sodium/ salt content; and (3) stop advertising unhealthy products on TV shows that kids watch frequently. This new index variable yielded a Chronbach alpha coefficient of 0.60 .

\section{Community-level EH}

Survey respondents were asked to provide a zip code, which were then linked to an internally developed EH Index, a composite score of six social and economic indicators that impact health (ie, crowded housing, poverty level, unemployment status, education status, dependency status and per capita income). A description of this index and its six indicators that the calculation is based on are described elsewhere. ${ }^{17}{ }^{34}$ It was recently updated in 2015 to encompass EH of LAC residents between 2008 and 2012; the updated index ranges from 13.2 to 82.9 (internal data, not published). The higher the index score, the greater the level of hardship. To establish cut-off points, these index rankings were divided in thirds - that is, respondents were classified as residing in 'low' EH communities if their zip codes corresponded to communities with $\mathrm{EH}$ rankings between 13.2 and 36.4, 'intermediate' $\mathrm{EH}$ if between 36.5 and 59.5, and 'high' EH if corresponding community rankings were $>59.6$. This categorisation was informed by prior research using similar cut-points. ${ }^{35}$ This measure was used in descriptive and multivariable regression analyses. For the latter analysis, the measure was included as a primary regressor.

\section{Political affiliation}

Survey respondents were recruited from a registrationbased sample which included party registration information. Pre-existing party registration categories included "Republican", "Democrat", "non-partisan/independent", or "Green/Libertarian/other party" affiliation. These four categories were used in descriptive analyses. For multivariable regression analyses, responses were categorized as 'Republican' if respondents pre-identified as "Republican" and 'Democrat' if respondents were preidentified as "Democrat." Owing to a small sample size of respondents who were preidentified as "Green/ Libertarian/other party", the category 'other party affiliation' was created to combine respondents whose political affiliation was "non-partisan/independent" or "Green/Libertarian/other party".

\section{Sociodemographics}

Sociodemographic information was collected using a standard set of questions internally used in all Field Research surveys. Collected sociodemographic information included (1) age, reported as whole numbers; (2) sex, classified as 'female' or 'male'; (3) race/ethnicity, classified as 'black', 'Hispanic', 'white', 'Asian/Pacific Islander', and 'other'; (4) education, classified as 'less than high school', 'high school graduate', 'some college or junior college', or 'college graduate or above'; and (5) annual household income, classified as ' $\angle 20000$ ', '\$20 000-\$39 000’, ‘\$40 000-\$59 000’, ‘60000-\$79 000’, '\$80 000-\$99 000' and '\$100 000+'. These measures were used in descriptive and multivariable regression analyses. However, in the regression models the education variable was excluded due to multicollinearity with the income variable. Moreover, the 'other' category for race/ethnicity was excluded due to a small sample size.

\section{Obesity-related perceptions}

Respondents were asked to indicate how serious a problem they believe obesity to be among LAC adults today using a question adapted from a childhood obesity prevention survey conducted by Field Research on behalf of the California Endowment. ${ }^{30}$ Respondents were asked, "How serious a problem do you believe obesity is among adults in Los Angeles County today?" Response options included "very serious," "somewhat serious," "not too serious," "not at all serious," and "don't know/refuse." In both descriptive and multivariable regression analyses, response options were dichotomized as 'believes to be a very serious problem' if they responded "very serious" and 'does not believe to be a very serious problem' if they responded "somewhat serious," "not too serious," or "not at all serious."

An internally developed question sought to understand the factors respondents believe play a larger role in determining whether a person is obese/seriously overweight. Respondents were asked, "Which do you think plays a larger role in determining whether a person is obese or seriously overweight?" Response options included "individual factors, such as a person's genetics and motivations," "environmental factors, such as their access to healthy foods and recreation," or "both are equally important." Response options were categorized as 'individual factors (e.g., genetics)' if they responded "individual factors," 'environmental factors (e.g., access)' if they responded "environmental factors," and "both individual and environmental factors' if they responded "both are equally important." This categorisation was used in descriptive and multivariable regression analyses.

\section{Self-reported health and weight status}

Health status was measured by asking respondents to indicate their perceived health status using a validated question from the Medical Outcomes Study Questionnaire Short Form 36 Health Survey. ${ }^{36}$ Respondents were asked, "In general [would you say] your health is excellent, very good, good, fair, or poor?" In both descriptive and multivariable regression analyses, response options were categorized as 'excellent' if they answered "excellent," 'very good/good' if they responded "very good" or "good," and 'fair/poor' if they responded "fair" or "poor."

Weight status was measured by asking respondents to indicate their perceived weight status using questions 
from the 2007 to 2008 National Health and Nutrition Examination Survey. ${ }^{37}$ Respondents were asked, "Do you consider yourself to be overweight or obese, about right or underweight?" Response options included "overweight/obese", "about right", "underweight," and "don't know/refuse". Responses were dichotomized as "normal/underweight' if they responded "about right" or "underweight" and 'overweight/obese' if they responded "overweight/obese." The measure operationalised in the manner described was used in descriptive and multivariable regression analyses.

\section{Nutrition label reading behaviours}

Respondents were asked to indicate their frequency of reviewing nutritional/calorie information posted on food packages before making food selections at supermarkets and grocery stores via an internally developed question. Respondents were asked, "When buying groceries at supermarkets and grocery stores, how often do you review the nutritional and calorie information posted on food packages before making your food selections?" Response options included "all of the time", "most of the time", "some of the time", "occasionally", "never," and "don't know/refuse". In both descriptive and multivariable regression analyses, responses were categorized as 'all/most of the time' if respondents answered "all of the time" or "most of the time" and "some/none of the time' if respondents answered "some of the time," "occasionally," or "never."

\section{Neighbourhood food environment}

Using internally developed questions, respondents were asked to report their ease of finding places with healthy food items. Respondents were asked, "How easy or difficult is it to find: (1) places selling fresh fruits and vegetables in your neighbourhood; (2) supermarkets/grocery stores in your neighbourhood; and (3) fresh and freely available drinking water in public spaces in your neighbourhood, such as local parks and schools?" To assess ease of finding unhealthy food items, respondents were asked, "How easy or difficult is it to find fast-food restaurants like McDonald's, Taco Bell, KFC or other similar types of places in your neighbourhood?" Response options for both questions included "very easy," "somewhat easy," "somewhat difficult," "very difficult," and "don't know/refused." In descriptive analyses, responses to these questions were dichotomized as "very easy to find' if they answered "very easy" and "not very easy to find' if they responded "somewhat easy," "somewhat difficult," and "very difficult."

In multivariable regression analyses, unhealthy eating was dichotomised the same as in descriptive analyses. However, healthy eating was converted into an index variable representing ease of respondents finding fresh fruit and vegetables, supermarkets/grocery stores, and fresh/freely available water in their neighbourhood. Responses were summated as an average of the three measures (excluding response options of 'don't know/ refused').

\section{Self-reported nutrition behaviours}

A series of internally developed questions sought to assess respondent nutrition behaviours. Respondents were asked, "In an average day, about how many servings of... (1) fruit do you eat, counting fresh, canned dried or frozen fruits?; and (2) vegetables do you eat, counting fresh, canned, dried and frozen vegetable?" For each question, respondents were asked to provide a whole number value. Responses were then converted into a continuous variable by summating the two measures.

To assess soda consumption, respondents were asked, "In an average week, about how many regular sodas such as Coke or Mountain Dew do you drink?" To assess restaurant food consumption respondents were asked the following: (1) "In an average week, how many times do you eat any food from a fast-food restaurant like McDonald's, Taco Bell, or KFC or another similar type of place?"; and (2) "In an average week, how many times do you eat any food from any type of sit-down restaurant, not counting fast-food restaurants?" Responses to each of these questions were provided as a whole number value and analysed as a continuous variable.

\section{Sample weighting}

As described by Field Research in their summary of methods used in the study survey, sample weights were created by developing control totals based on two priority regions of LAC (ie, Los Angeles and South Los Angeles)-that is, those reflecting each jurisdiction's share of the total registered LAC voter population. ${ }^{38}$ Voter count information from the LAC Registrar of Voters were used to derive the total registered voter population across LAC. Counts were then subdivided countywide and by the two regions of interest-by party registration, Service Planning Area (SPA), age, and gender. Field Research used this information to assure that all samples properly aligned to population proportions across key dimensions (ie, party registration, SPA, age and gender).

\section{Analysis plan}

All data were cleaned, managed, and analysed using Stata V.14.1 (StataCorp LP, College Station, Texas, USA) with weighted data reflecting the LAC population's sociodemographic characteristics. Descriptive analyses were performed to compare and contrast attitudes towards obesity epidemic, nutrition knowledge and behaviours, public opinions about changing business practices/government policies, and sociodemographics by three levels of community $\mathrm{EH}$. A series of $\chi^{2}$ tests were conducted to examine differences between the groups across all categorical variables of interest. In regression analyses, to find out if and how policies/practices grouped into coinciding clusters, a factor analysis on the 12 PSEs was performed to inform variable 
selection. For example, latent variables identified from a factor analysis informed outcome variable selection (ie, index of level of public support for PSEs). In addition to using a conceptual framework (not shown), variable inclusion in the multivariable models were guided by univariate, bivariate and correlation analyses. Multivariable models corresponding to the three identified outcome variables were performed to describe the associations between mean level of policy support and community EH. Responses of "other/ don't know" or responses with $<5 \%$ were set as missing. Since data were missing at random, list-wise deletion was conducted to obtain the final analysis sample. ${ }^{39}$ F-test statistics were used to gauge the overall significance of multivariable models and t-tests for parameter significance.

\section{RESULTS}

In total, 1007 interviews were completed (crude response rate $26.3 \%$, cooperation rate $65.7 \%$ ). Descriptive statistics are presented for this sample. For the regression analyses, the analysis sample included 757 respondents.

Significant differences in party affiliation, race/ethnicity, education and income were observed between respondents residing in 'low', 'intermediate,' and 'high' EH communities (table 2). Similarly, significant differences were observed in selected indicators of obesity-related perceptions, food environment in the neighbourhood, self-reported health, and weight status, and restaurant meal (ie, fast-food and sit-down) consumption (table 3). While it appeared there was less support among respondents across the three $\mathrm{EH}$ groups for PSE domains classified as 'limiting/restrictive' versus 'incentivising/promotional,' and/or 'changing business practices' (table 4), significant group differences by respondents' community $\mathrm{EH}\left(\chi^{2} \mathrm{p}<0.05\right)$ were observed in the levels of public support for some policies/practices in all three domains.

Although multivariable analyses suggested community EH was not a significant predictor of level of support for any of the three types of PSEs after controlling for other covariates (table 5), this was not entirely the case for respondents who strongly believed obesity is a serious problem in LAC; the latter group reported strong support for 'promotional/incentivising' (parameter estimate $(\beta)=0.261$, 95\% CI 0.166 to 0.356 ), 'limiting/restrictive' ( $\beta=0.356,95 \%$ CI 0.244 to 0.468$)$, and 'changing business practices' $(\beta=0.275,95 \%$ CI 0.178 to 0.372) PSEs. Females also appeared to strongly support these three PSE domains: 'promotional/incentivising' ( $\beta=0.179,95 \%$ CI 0.094 to 0.264$)$, 'limiting/restrictive' $(\beta=0.203$, 95\% CI 0.093 to 0.313$)$, and 'changing business practices' $(\beta=0.145,95 \%$ CI 0.049 to 0.240$)$. In contrast, respondents who were identified as 'Republican' were less likely to support PSEs across the three domains: 'promotional/incentivising' $(\beta=-0.205,95 \% \mathrm{CI}-0.326$ to $-0.085)$, 'limiting/restrictive' $(\beta=-0.350,95 \%$ CI -0.504 to -0.196 , and 'changing business practices' $(\beta=-0.343$, $95 \%$ CI -0.476 to -0.209$)$.

Other predictors of PSE support included age, race/ ethnicity, income, beliefs pertaining to underlying causes of obesity, nutrition label reading behaviours, ease of finding healthy foods, and patterns of fruit and vegetable consumption (table 5); however, their significance level varied across the three types of PSEs.

\section{DISCUSSION}

This is among the first analyses to examine predictors of public support for PSE change strategies that are part of recent obesity prevention investments in LAC. This analysis is particularly timely given ongoing dialogue and activities related to the Patient Protection and Affordable Care Act of 2010, ${ }^{40}$ especially in regard to chronic disease prevention investments and how best to maximise taxpayers' dollars to promote health.

In multivariable analyses, community $\mathrm{EH}$ was examined as a primary predictor of public support of PSEsthat is, included as a primary regressor. Results from these analyses suggest there are no statistically significant differences in policy support for any of the three types of PSEs by community EH, after controlling for covariates. A number of factors may have contributed to this. One such example is the null finding, which could be the result of emerging social norms-that is, the public views nutrition-focused PSE interventions in more favourable light than years past. Albeit in a paucity of studies that have examined public opinions related to nutrition-focused PSE efforts, there are only a few that provided support for this hypothesis. A study of public opinions using a nationally representative sample of adults conducted in 2004 found that support for "increasing the tax on fast food and less healthy foods marketed to children" was about $43.9 \%$ among a nationally representative sample of adults. ${ }^{20}$ Similarly, another nationally representative survey found that only about $28.4 \%$ of survey respondents supported imposing "a tax on junk food similar to existing government taxes on cigarettes and alcohol". ${ }^{26}$ Results from a 2011 survey that focused on examining local-level public opinions related to physical activity and healthy eating suggest junk foodtype policies have garnered greater public support in recent years. Specifically, about $91 \%$ of survey respondents favored taxing sodas and soft drinks as an obesity prevention strategy. ${ }^{28}$ Yet, there are a number of limitations to drawing comparisons across these various surveys given differences in the measures and sampling procedures. Clearly more research on this topic is needed.

Another possible explanation for the absence of an association between community EH and PSE support could be the consequence of varied support in each of the three types of PSEs among the 'low', 'intermediate,' and 'high' EH groups. The present study, for example, 
Table 2 Characteristics of respondents by community economic hardship status, the Los Angeles County Food and Nutrition Field Survey, $2013(\mathrm{n}=1007)^{*}$

\begin{tabular}{|c|c|c|c|c|c|}
\hline \multirow[b]{2}{*}{ Characteristics } & \multicolumn{4}{|c|}{ Weighted prevalence } & \multirow[b]{2}{*}{ p Valueף } \\
\hline & $\begin{array}{l}\text { Full sample } \\
\%(n) \\
100(1007)\end{array}$ & $\begin{array}{l}\text { 'Low economic } \\
\text { hardship'† } \\
\% \text { (n) } \\
26.6(198)\end{array}$ & $\begin{array}{l}\text { 'Intermediate } \\
\text { economic } \\
\text { hardship’ } \\
\%(n) \\
46.1(320)\end{array}$ & $\begin{array}{l}\text { ‘High } \\
\text { economic } \\
\text { hardship'§ } \\
\%(n) \\
27.3(489)\end{array}$ & \\
\hline \multicolumn{5}{|l|}{ Party affiliation } & $<0.05^{\star \star}$ \\
\hline Republican & $21.5(172)$ & $21.8(41)$ & $26.3(82)$ & $13.0(49)$ & \\
\hline Democrat & $50.9(565)$ & $50.1(104)$ & $45.9(145)$ & $60.1(316)$ & \\
\hline Non-partisan/independent & 23.1 (229) & $22.2(41)$ & $23.6(78)$ & $23.2(110)$ & \\
\hline $\begin{array}{l}\text { Green/Libertarian/other } \\
\text { party }\end{array}$ & $4.5(41)$ & $5.9(12)$ & $4.2(15)$ & $3.7(14)$ & \\
\hline \multicolumn{5}{|l|}{ Sex } & - \\
\hline Female & $53.6(550)$ & 53.3 (105) & 50.3 (159) & $60.4(286)$ & \\
\hline Male & $46.4(457)$ & $46.7(93)$ & $49.7(161)$ & $39.6(203)$ & \\
\hline \multicolumn{5}{|l|}{ Age (years) } & - \\
\hline $18-24$ & $12.9(161)$ & $10.6(22)$ & $11.5(44)$ & $17.5(95)$ & \\
\hline $25-44$ & 34.3 (352) & $36.2(74)$ & $34.1(111)$ & 32.9 (167) & \\
\hline $45-64$ & 34.1 (303) & 32.9 (59) & $35.1(95)$ & 33.7 (149) & \\
\hline $65+$ & $18.7(175)$ & $20.3(41)$ & $19.3(64)$ & $15.9(70)$ & \\
\hline \multicolumn{5}{|l|}{ Race/ethnicity } & $<0.001^{* *}$,††,㧊 \\
\hline Black & $9.1(207)$ & $5.4(13)$ & $10.1(34)$ & $11.2(160)$ & \\
\hline Hispanic/Latino & $38.9(408)$ & $16.7(30)$ & 37.7 (123) & $62.7(255)$ & \\
\hline White & $40.0(283)$ & $64.8(128)$ & 36.4 (113) & $18.3(42)$ & \\
\hline Asian/Pacific Islander & $8.8(64)$ & $9.3(19)$ & $11.6(35)$ & $3.7(10)$ & \\
\hline Other & $4.1(45)$ & $3.8(8)$ & $4.3(15)$ & $4.2(22)$ & \\
\hline \multicolumn{5}{|l|}{ Education } & $<0.001^{\star \star}$,††,㧊 \\
\hline Less than high school & $10.6(144)$ & $2.8(6)$ & $7.2(24)$ & $24.0(114)$ & \\
\hline High school graduate & $17.0(213)$ & $9.9(19)$ & $19.8(62)$ & $19.2(132)$ & \\
\hline $\begin{array}{l}\text { Some college or junior } \\
\text { college }\end{array}$ & 31.1 (312) & 25.9 (49) & $31.2(104)$ & 35.8 (159) & \\
\hline College graduate or above & $41.3(330)$ & $61.5(121)$ & $41.8(129)$ & $21.0(80)$ & \\
\hline \multicolumn{5}{|l|}{ Income } & $<0.001^{* \star}$,十七,㧊 \\
\hline Under \$20 000 & $21.0(269)$ & $14.5(26)$ & $16.2(46)$ & 35.1 (197) & \\
\hline$\$ 20000-\$ 39999$ & $21.6(203)$ & $14.9(26)$ & $23.0(65)$ & 25.7 (112) & \\
\hline$\$ 40000-\$ 59000$ & $15.5(130)$ & $10.9(20)$ & $17.4(47)$ & $17.1(63)$ & \\
\hline$\$ 60000-\$ 79000$ & $13.8(97)$ & $16.4(28)$ & $13.9(37)$ & $11.3(32)$ & \\
\hline$\$ 80000-\$ 99999$ & $8.1(53)$ & $11.8(21)$ & 7.0 (19) & $6.1(13)$ & \\
\hline$\$ 100000$ or more & 20.0 (123) & $31.6(57)$ & $22.5(56)$ & $4.7(10)$ & \\
\hline \multicolumn{6}{|c|}{ 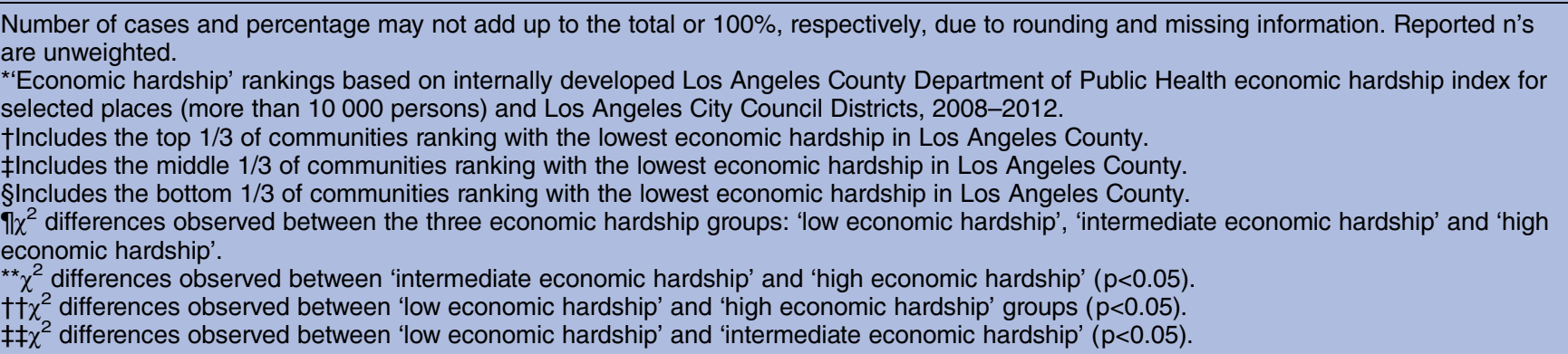 } \\
\hline
\end{tabular}

found that public support for PSEs such as encouraging food and beverage companies to change the ingredients in their products to reduce their calories or sodium were statistically different across the three groups.

In contrast to community EH, Republican affiliation, being female, and perceiving obesity to be a serious health issue were found to significantly predict public support for the three types of PSEs. In particular, respondents who were identified as 'Republican' appeared less likely to support any of the three types of PSEs. This makes sense given the nature of the Republican party, which has historically been more socially and fiscally conservative, especially in regard to welfare policies or practices. ${ }^{41}$ A prior study examining 
Table 3 Comparison of obesity-related perceptions, self-reported health and weight status, self-reported nutrition behaviours, nutrition label reading behaviours, and neighbourhood food environment among respondents by community economic hardship status, the Los Angeles County Food and Nutrition Field Survey, 2013*

\begin{tabular}{|c|c|c|c|c|c|}
\hline \multirow[b]{2}{*}{ Characteristics } & \multicolumn{4}{|c|}{ Weighted prevalence or mean } & \multirow[b]{2}{*}{ p valueף } \\
\hline & $\begin{array}{l}\text { Full } \\
\text { sample }\end{array}$ & $\begin{array}{l}\text { 'Low economic } \\
\text { hardship'† }\end{array}$ & $\begin{array}{l}\text { 'Intermediate economic } \\
\text { hardship'‡ }\end{array}$ & $\begin{array}{l}\text { ‘High economic } \\
\text { hardship'§ }\end{array}$ & \\
\hline$\%(n)$ & $100(1007)$ & $26.6(198)$ & $46.1(320)$ & $27.3(489)$ & \\
\hline \multicolumn{6}{|l|}{ Obesity-related perceptions, \% (n) } \\
\hline $\begin{array}{l}\text { Obesity among Los Angeles County adults is a very serious } \\
\text { problem }\end{array}$ & & & & & $<0.05^{\star \star}$ \\
\hline Believes to be a very serious problem & $60.7(620)$ & $53.8(99)$ & $61.2(188)$ & $66.4(333)$ & \\
\hline Does not believe to be a very serious problem & $39.3(361)$ & $46.2(89)$ & $38.8(126)$ & $33.6(146)$ & \\
\hline $\begin{array}{l}\text { Obesity among Los Angeles County children is a very serious } \\
\text { problem, \% (n) }\end{array}$ & & & & & $<0.01^{\star *}, \dagger \dagger$ \\
\hline Believes to be a very serious problem & $61.4(625)$ & $52.1(98)$ & $63.3(194)$ & $67.3(333)$ & \\
\hline Does not believe to be a very serious problem & $38.6(359)$ & $47.9(91)$ & $36.8(115)$ & $32.7(153)$ & \\
\hline $\begin{array}{l}\text { Factors that play a larger role in determining an individual's obesity } \\
\text { status, } \%(n)\end{array}$ & & & & & - \\
\hline Individual factors (eg, genetics) & $10.8(93)$ & $12.8(23)$ & $11.3(35)$ & $8.0(35)$ & \\
\hline Environmental factors (eg, access) & $12.2(120)$ & $12.1(24)$ & $12.8(42)$ & $11.3(54)$ & \\
\hline Both individual and environmental factors & $77.0(774)$ & $75.1(148)$ & $75.9(236)$ & $80.7(390)$ & \\
\hline \multicolumn{6}{|l|}{ Self-reported health and weight status, \% (n) } \\
\hline Self-reported health status & & & & & 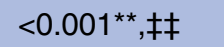 \\
\hline Excellent & $18.9(171)$ & $27.5(55)$ & $19.6(59)$ & $9.2(57)$ & \\
\hline Very good/good & $63.6(608)$ & $62.8(122)$ & $66.9(212)$ & $58.8(274)$ & \\
\hline Fair/poor & $17.5(214)$ & $9.6(20)$ & $13.5(43)$ & $32.0(151)$ & \\
\hline Perceived weight status, \% (n) & & & & & $<0.01^{\star *}, \dagger \dagger$ \\
\hline Overweight/obese & $29.8(298)$ & $18.0(35)$ & $32.0(96)$ & $37.6(167)$ & \\
\hline Normal/underweight & $70.2(692)$ & $82.0(162)$ & $68.0(220)$ & $62.4(310)$ & \\
\hline \multicolumn{6}{|l|}{ Self-reported nutrition behaviours, mean (SE) } \\
\hline Fruit and vegetable consumption & $2.35(0.05)$ & $2.54(0.10)$ & $2.34(0.07)$ & $2.18(0.08)$ & - \\
\hline Non-diet soda consumption & $1.21(0.10)$ & $0.92(0.15)$ & $1.15(0.17)$ & $1.60(0.17)$ & - \\
\hline Fast-food restaurant meal consumption & $1.11(0.05)$ & $0.87(0.09)$ & $1.10(0.08)$ & $1.30(1.09)$ & $<0.001^{\star *}$,十†,㧊 \\
\hline Sit-down restaurant meal consumption & $1.46(0.07)$ & $2.13(0.17)$ & $1.35(0.09)$ & $1.00(0.08)$ & 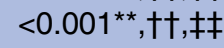 \\
\hline \multicolumn{6}{|l|}{ Reading nutrition labelling when grocery shopping, \% (n) } \\
\hline $\begin{array}{l}\text { Frequency reviewing nutritional and calorie information posted on } \\
\text { food packages before making food selection decisions }\end{array}$ & & & & & - \\
\hline All/most of the time & $55.5(518)$ & $57.3(113)$ & $56.2(174)$ & $52.3(231)$ & \\
\hline Some/none of the time & $44.5(477)$ & $42.7(83)$ & $43.8(144)$ & $47.7(250)$ & \\
\hline \multicolumn{6}{|l|}{ Neighbourhood food environment, \% ( $n$ ) } \\
\hline Fresh fruits and vegetable access & & & & & $<0.001^{\star *}$,十†, 㧊 \\
\hline Very easy to find & $60.0(518)$ & $72.9(144)$ & $59.8(185)$ & $47.7(189)$ & \\
\hline Not very easy to find & $40.0(474)$ & $27.1(52)$ & $40.3(131)$ & $52.3(291)$ & \\
\hline Supermarkets and grocery store access, \% (n) & & & & & $<0.001^{* *}$,††, 㧊 \\
\hline Very easy to find & $75.1(702)$ & $88.1(172)$ & $74.3(237)$ & $64.0(293)$ & \\
\hline
\end{tabular}




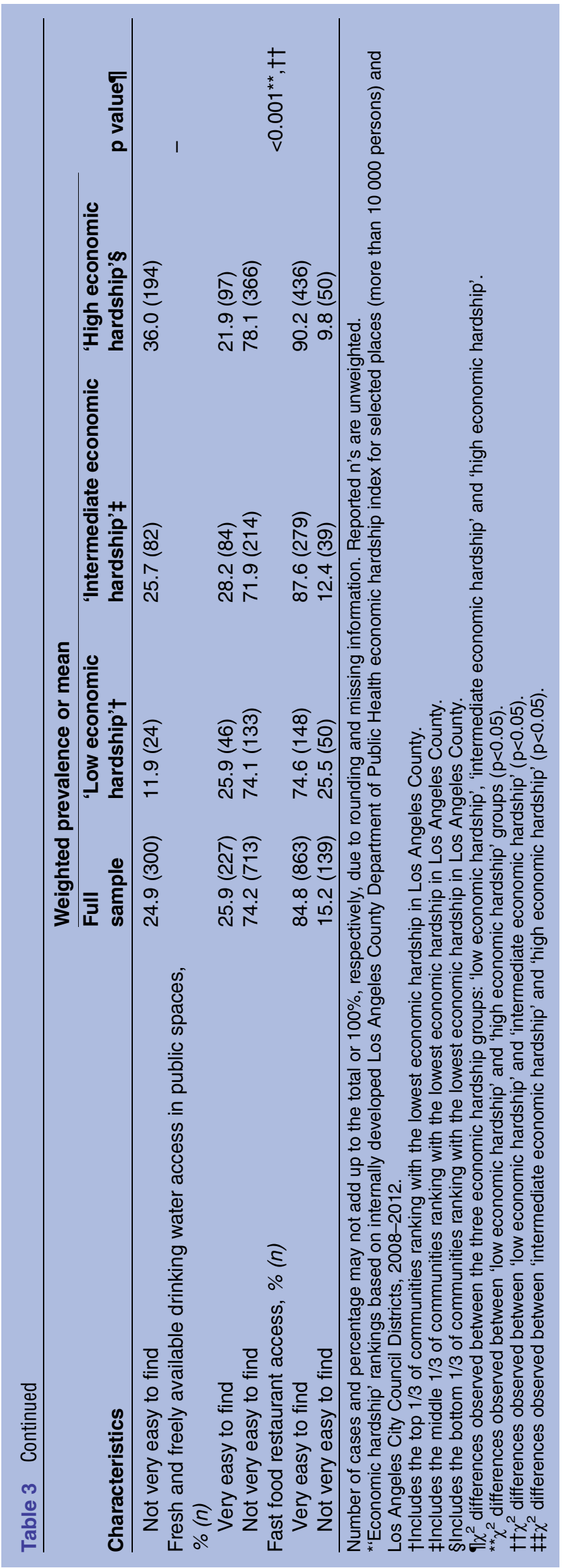

public response to media messages related to social determinants of type 2 diabetes, for instance, found that Republicans expressed less support than Democrats (and Independents) for prospective public health policies related to addressing underlying determinants of diabetes. ${ }^{42}$ In terms of sex, our study found that females are more likely to support the three types of PSEs. This result is not too surprising; similar results have been observed in other public opinion studies of obesity prevention strategies. ${ }^{20} 2843$ Moreover, in LAC, females (compared with males) have been found to be more invested in their health and those of their families. ${ }^{11} 12$ Finally (and not surprisingly), individuals who perceived obesity to be a serious issue among LAC adults appeared more supportive of the three types of PSEs than those who did not. While no prior studies have explicitly examined perceived obesity severity as a predictor of public support for nutrition-related PSEs, similar findings have been found elsewhere. For instance, Tabak $e t a l^{28}$ found greater level of support for healthy eating and physical activity policies among individuals living in counties with higher levels of obesity.

Other results from the present study were also consistent with the literature, especially as they relate to socioeconomic status and health risk behaviours. Our study showed, for example, significant sociodemographic and environmental disparities among the local communities by the three EH levels. Respondents in the 'low' EH communities were primarily white, had incomes $>\$ 100000$ and reported greater access to fresh fruits and vegetables. In contrast, respondents residing in 'high' EH communities were primarily Hispanic/ African-American, had incomes $<\$ 20000$, and reported difficulty accessing fresh fruits and vegetables. National and local health statistics support these observations. Latinos and blacks typically have lower socioeconomic status, ${ }^{17}{ }^{44}$ as well as higher obesity and related cardiovascular risks than their more affluent counterparts. ${ }^{17} 4546$

Finally, while not the main objective of the study, results from the descriptive analyses suggest that public support varied by the type of strategies and whether these strategies impinged on personal choice. The 'restrictive' policies/practices (ie, intrusive) were generally less well received. For example, policies prohibiting supermarkets from selling unhealthy foods received unilaterally lower public support regardless of community EH status. Prior research affirms a similar pattern in the literature. 'Restrictive' policy interventions have typically received less favourable public support than 'nonrestrictive' ones. ${ }^{21} 27$

\section{Limitations}

In spite of its strengths-which included a comprehensive profile of public support for PSE changes across the different segments of the LAC population-the present study had several limitations. First, social desirability bias may have resulted in a number of the respondents over- 
Table 4 Comparison of public opinions of policy, systems and environmental change policies/practices among respondents by community economic hardship status, the Los Angeles County Food and Nutrition Field Survey, 2013*

\begin{tabular}{|c|c|c|c|c|c|c|}
\hline & \multirow[b]{2}{*}{ Characteristics } & \multicolumn{4}{|c|}{ Weighted prevalence } & \multirow[b]{2}{*}{ p Valueף } \\
\hline & & $\begin{array}{l}\text { Full } \\
\text { sample }\end{array}$ & $\begin{array}{l}\text { 'Low } \\
\text { economic } \\
\text { hardship'† }\end{array}$ & $\begin{array}{l}\text { 'Intermediate } \\
\text { economic } \\
\text { hardship’ł }\end{array}$ & $\begin{array}{l}\text { ‘High } \\
\text { economic } \\
\text { hardship'§ }\end{array}$ & \\
\hline & & $\%(n)$ & $\%(n)$ & $\%(n)$ & $\%(n)$ & \\
\hline & & $100(1007)$ & $26.6(198)$ & $46.1(320)$ & $27.3(489)$ & \\
\hline \multirow{13}{*}{$\begin{array}{l}\text { Incentivising/ } \\
\text { promotional policies } \\
\text { and practices }\end{array}$} & Respondent support of policies/practices that seek to: & & & & & \\
\hline & $\begin{array}{l}\text { Attract more supermarkets selling fresh fruits and } \\
\text { vegetables in low-income neighbourhoods }\end{array}$ & & & & & $<0.05^{\star \star}, \dagger \dagger$ \\
\hline & Favours strongly & $76.8(776)$ & $74.9(150)$ & 73.5 (229) & $84.0(397)$ & \\
\hline & Does not favour strongly & $23.2(216)$ & $25.1(47)$ & $26.5(83)$ & $16.0(86)$ & \\
\hline & $\begin{array}{l}\text { Attract more farmers markets and produce stands } \\
\text { selling fresh fruits and vegetables in low-income } \\
\text { neighbourhoods }\end{array}$ & & & & & - \\
\hline & Favours strongly & $78.6(777)$ & $78.1(153)$ & $76.2(235)$ & $83.0(389)$ & \\
\hline & Does not favour strongly & $21.4(217)$ & $21.9(42)$ & $23.8(77)$ & $17.0(98)$ & \\
\hline & $\begin{array}{l}\text { Increase the availability of fresh drinking water at local } \\
\text { parks, schools and other public areas }\end{array}$ & & & & & $<0.05^{\star *}$,拉 \\
\hline & Favours strongly & $79.6(804)$ & $72.6(139)$ & $81.0(255)$ & $84.0(410)$ & \\
\hline & Does not favour strongly & $20.4(184)$ & $27.5(51)$ & $19.0(60)$ & $16.0(73)$ & \\
\hline & $\begin{array}{l}\text { Provide local grocery and convenience stores with tax } \\
\text { credits and other incentives to encourage sale of } \\
\text { healthy foods and to reduce the number of unhealthy } \\
\text { foods and snacks sold }\end{array}$ & & & & & $<0.01^{\star *}, \dagger \dagger$ \\
\hline & Favour strongly & $60.1(620)$ & $54.5(103)$ & $57.7(184)$ & $69.4(333)$ & \\
\hline & Does not favour strongly & 39.9 (368) & $45.6(88)$ & $42.3(132)$ & $30.6(148)$ & \\
\hline \multirow{10}{*}{$\begin{array}{l}\text { Limiting/restrictive } \\
\text { policies and practices }\end{array}$} & Respondent support of policies/practices that seek to: & & & & & \\
\hline & $\begin{array}{l}\text { Limit the container sizes in which sodas and other } \\
\text { sugary drinks can be sold in restaurants, snack bars, } \\
\text { movie theatres and sports arenas to no more than } 16 \\
\text { ounces }\end{array}$ & & & & & $<0.05^{\star \star}, \dagger \dagger$ \\
\hline & Favours strongly & $42.9(439)$ & $37.2(72)$ & $41.2(127)$ & $51.2(240)$ & \\
\hline & Does not favour strongly & $57.1(537)$ & $62.8(116)$ & $58.8(185)$ & $48.9(236)$ & \\
\hline & $\begin{array}{l}\text { Prohibit supermarkets from selling unhealthy food items, } \\
\text { like candy products, in their check-out aisles }\end{array}$ & & & & & - \\
\hline & Favours strongly & $29.3(291)$ & $26.1(49)$ & $29.5(88)$ & $31.9(154)$ & \\
\hline & Does not favour strongly & $70.7(668)$ & 73.9 (133) & $70.5(217)$ & $68.1(318)$ & \\
\hline & $\begin{array}{l}\text { Limit the number of fast food restaurants that a } \\
\text { community can have }\end{array}$ & & & & & - \\
\hline & Favours strongly & $37.8(404)$ & $34.9(67)$ & $36.0(111)$ & $43.5(226)$ & \\
\hline & Does not favour strongly & $62.3(564)$ & $65.1(120)$ & $64.0(195)$ & $56.6(249)$ & \\
\hline
\end{tabular}




\begin{tabular}{|c|c|c|c|c|c|c|}
\hline & \multirow[b]{2}{*}{ Characteristics } & \multicolumn{4}{|c|}{ Weighted prevalence } & \multirow[b]{2}{*}{ p Valueף } \\
\hline & & $\begin{array}{l}\text { Full } \\
\text { sample }\end{array}$ & $\begin{array}{l}\text { 'Low } \\
\text { economic } \\
\text { hardship'† }\end{array}$ & $\begin{array}{l}\text { 'Intermediate } \\
\text { economic } \\
\text { hardship’ }\end{array}$ & $\begin{array}{l}\text { 'High } \\
\text { economic } \\
\text { hardship'§ }\end{array}$ & \\
\hline & $\begin{array}{l}\text { Strengthen school nutrition standards to limit the types } \\
\text { of unhealthy foods and sugary drinks sold in the } \\
\text { schools }\end{array}$ & & & & & \\
\hline & Favours strongly & $73.8(729)$ & $77.1(151)$ & $72.9(230)$ & $72.2(348)$ & \\
\hline & Does not favour strongly & $26.2(267)$ & $23.0(45)$ & $27.1(87)$ & $27.8(135)$ & \\
\hline & $\begin{array}{l}\text { Reduce access to unhealthy snacks and sugary drinks } \\
\text { in vending machines in public buildings and work sites }\end{array}$ & & & & & $<0.05^{\star \star}, \mathrm{\dagger}$ \\
\hline & Favour strongly & $44.6(457)$ & $40.2(79)$ & $42.7(132)$ & $51.9(246)$ & \\
\hline & Does not favour strongly & $55.4(531)$ & $59.8(113)$ & $57.3(57.3)$ & $48.1(235)$ & \\
\hline \multirow[t]{9}{*}{$\begin{array}{l}\text { Changing business } \\
\text { practices }\end{array}$} & $\begin{array}{l}\text { Respondent support of policies/practices that seek to: } \\
\text { Encourage food and beverage companies to change the } \\
\text { ingredients in their products to reduce their calories? }\end{array}$ & & & & & $<0.001^{* *}$,†十,㧊 \\
\hline & Not very important & $60.8(634)$ & $49.4(96)$ & $59.5(186)$ & 73.9 (352) & \\
\hline & Not very important & $39.2(347)$ & $50.6(94)$ & $40.5(126)$ & $26.1(127)$ & \\
\hline & $\begin{array}{l}\text { Encourage food and beverage companies to change the } \\
\text { ingredients in their products to reduce their sodium or } \\
\text { salt content? }\end{array}$ & & & & & $<0.001^{* *}$,††,㧊 \\
\hline & Not very important & $71.5(725)$ & $61.5(123)$ & $72.2(226)$ & $80.1(376)$ & \\
\hline & Somewhat important & $28.5(271)$ & $38.5(72)$ & $27.8(89)$ & $19.9(110)$ & \\
\hline & $\begin{array}{l}\text { Encourage food and beverage companies to stop } \\
\text { advertising unhealthy products, like fast food and sodas, } \\
\text { on TV shows that kids watch frequently? }\end{array}$ & & & & & - \\
\hline & Not very important & $62.0(617)$ & $58.0(116)$ & $61.9(193)$ & $65.9(308)$ & \\
\hline & Somewhat important & $38.1(374)$ & $42.0(79)$ & $38.1(119)$ & $34.1(176)$ & \\
\hline \multicolumn{7}{|c|}{ 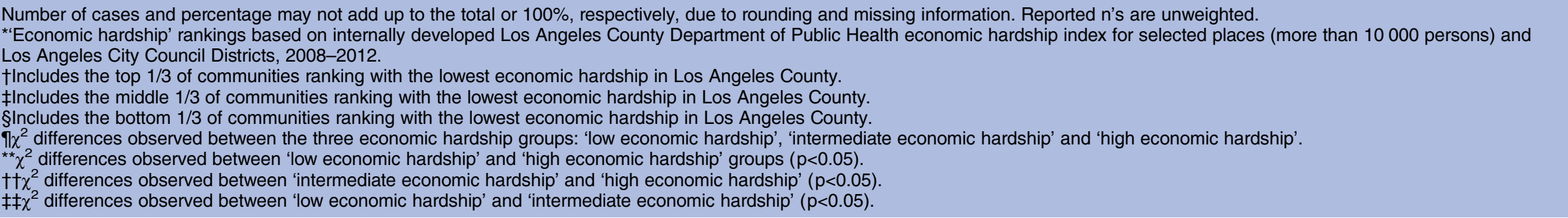 } \\
\hline
\end{tabular}


Table 5 Multiple linear regression models describing the predictors of public support for nutrition-focused policy, systems and environmental change policies/practices in Los Angeles County, results from the Los Angeles County Food and Nutrition Field Survey, $2013(n=757) \dagger$

\section{Primary regressor Community EH (ref: high EH) \\ Low EH}

Intermediate $\mathrm{EH}$

Control variables

Political affiliation (ref: Democrat)

Republican

Other political party/affiliation

Sex (ref: male)

Female

Age (continuous)

Race (ref: white)

African-American

Hispanic

Asian/Pacific Islande

Income (ref: $<\$ 20000$ )

$\$ 20000-\$ 39999$

$\$ 40$ 000-\$59 999

$\$ 60000-\$ 79999$

$\$ 80000-\$ 99999$

$\$ 100000+$

Independent variables

Believes that

Believes

Factors believe

Individual

Environmental

Health status (ref: excellent)

Very good/good

Fair/poor

Weight status (ref: overweight/obese)

Normal/underweigh

Frequency reading nutritional/calorie information posted on food packages (re

All/most of the time

Ease of finding unhealthy foods (ref: not very easy)

Very easy

Ease of finding healthy foods (continuous)

Fruit and vegetable consumption (continuous)

Non-diet soda consumption (continuous)

Fast-food restaurant meal consumption

(continuous)
Model 1: promotional/incentivising Model 2: limiting/restrictive

policiesł

Coefficient $(95 \% \mathrm{Cl})+\mathrm{t}$

$0.010(-0.115$ to 0.135$)$

$-0.014(-0.103$ to 0.074$)$

$-0.205(-0.326 \text { to }-0.085)^{\star \star}$

$-0.054(-0.152$ to 0.045$)$

$0.179(0.094 \text { to } 0.264)^{* * *}$

$-0.003(-0.006 \text { to }-0.000)^{\star}$

$0.062(-0.083$ to 0.207$)$

$0.058(-0.051$ to 0.167$)$

0.127 (-0.005 to 0.260$)$

$0.087(-0.045$ to 0.219$)$

$0.052(-0.094$ to 0.198$)$

$0.108(-0.051$ to 0.266$)$

$0.120(-0.025$ to 0.265$)$

-0.146 ( -0.318 to 0.026$)$ policies§

Coefficient (95\% Cl)t†

0.103 (-0.068 to 0.274$)$

$-0.013(-0.148$ to 0.122$)$

$-0.350(-0.504 \text { to }-0.196)^{\star \star \star}$

$-0.077(-0.202$ to 0.049$)$

$0.203(0.093 \text { to } 0.313)^{\star * *}$

$-0.003(-0.006$ to 0.001$)$

$0.023(-0.165$ to 0.211$)$

0.066 ( -0.089 to 0.220$)$

$0.239(0.004 \text { to } 0.474)^{*}$

$-0.080(-0.228$ to 0.069$)$

$-0.040(-0.214$ to 0.134$)$

$0.013(-0.184$ to 0.211$)$

-0.039 ( -0.278 to 0.201$)$

$-0.253(-0.456 \text { to }-0.051)^{*}$
Model 3: changing business practices

Coefficient $(95 \% \mathrm{Cl})+\dagger$

$0.041(-0.107$ to 0.189$)$

$0.048(-0.069$ to 0.166$)$

$-0.343(-0.476 \text { to }-0.209)^{\star \star}$

$-0.115(-0.224 \text { to }-0.006)^{*}$

$0.145(0.049 \text { to } 0.240)^{\star \star}$

$0.001(-0.002$ to 0.004$)$

$0.113(-0.050$ to 0.276$)$

$0.139(0.005 \text { to } 0.274)^{*}$

$0.040(-0.164$ to 0.244$)$

$0.009(-0.120$ to 0.138$)$

$0.041(-0.110$ to 0.192$)$

$0.128(-0.043$ to 0.300$)$

$-0.030(-0.238$ to 0.177$)$

$-0.190(-0.366 \text { to }-0.014)^{\star}$

$0.275(0.178 \text { to } 0.372)^{\star \star \star}$

$-0.212(-0.369 \text { to }-0.054)^{\star \star}$

$0.063(-0.081$ to 0.206$)$

$0.034(-0.092$ to 0.160$)$

0.057 ( -0.105 to 0.219$)$

$0.057(-0.045$ to 0.158$)$

$0.173(0.078 \text { to } 0.267)^{\star * *}$

$0.030(-0.099$ to 0.159$)$

$0.020(-0.050$ to 0.091$)$

$-0.022(-0.056$ to 0.012$)$

$-0.006(-0.021$ to 0.009$)$

$-0.007(-0.035$ to 0.021$)$ 


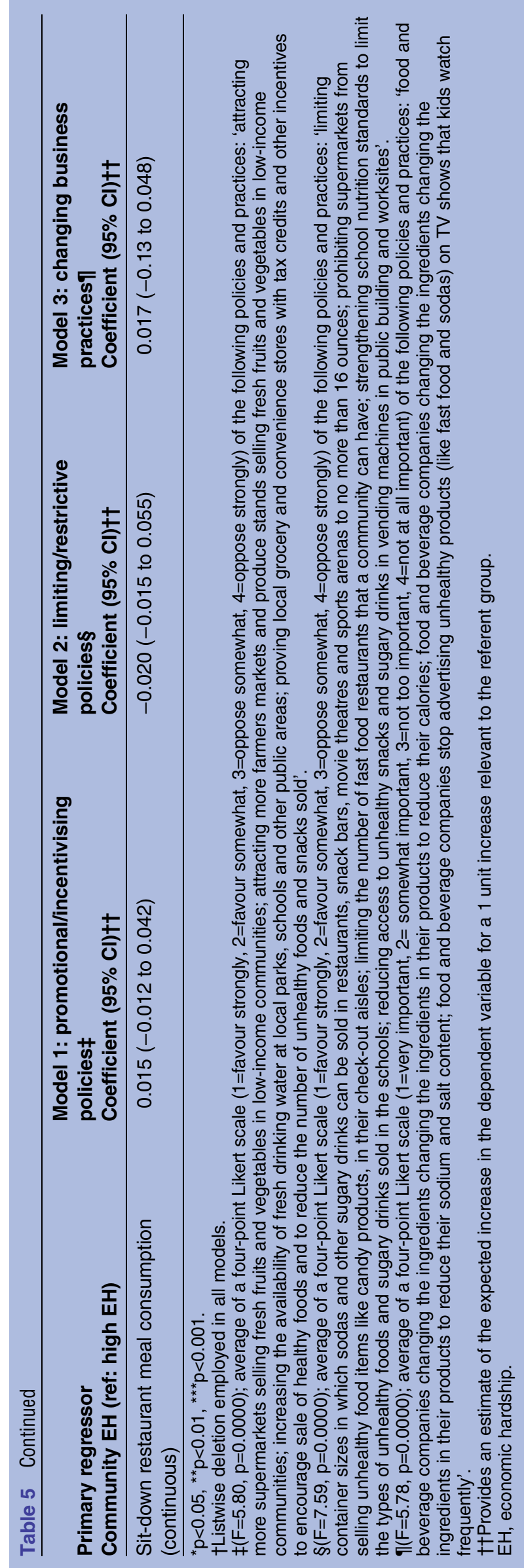

reporting their level of policy support. Second, although respondent zip codes were aligned to correspond with the communities listed in the EH Index, this geographic analysis approach is not entirely precise; that is, zip codes did not always coincide exactly with community boundaries. This may have resulted in some respondent misclassification of community EH. Third, as with any surveys, limited response and cooperation rates among respondents may have led to self-selection bias. Moreover, if non-response was greater among those residing in communities with greater community $\mathrm{EH}$, this may have resulted in a sample population that is more homogeneous in socioeconomic characteristics than is typically found in LAC; consequently, this might have led to underestimation of potential policy support across the three community EH levels. Fourth, some survey questions were internally developed and fielded; thus, we did not have reliable and valid estimates for all of the measures of interest. However, when feasible, the survey included questions adapted from previously validated surveys or previously administered surveys in an effort to diminish question bias. In addition, all survey questions were pretested prior to start of fullscale data collection. Fifth, landline telephone surveys have historically been subject to over-representation of persons with higher socioeconomic status ${ }^{47}$-and this may have been the case in the present survey. To mitigate this issue, however, cell phone numbers and other voter-specific information were leveraged to increase representativeness. Sixth, the moderate Chronbach alpha for the new index policy support variable suggests the measure of policy support is less reliable than intended and could have introduced bias to study results. Lastly, the generalizability of the findings may be limited, given the survey included two augmented samples of voters residing in two distinct Los Angeles County regions.

\section{CONCLUSION}

While millions of federal dollars have been invested to combat obesity nationwide, obesity prevalence among Americans remains high. Recent PSE investments, in particular, have been disseminated in communities at risk for obesity, but generally without a priori assessments of these communities' receptivity to these interventions. Ameliorating high obesity prevalence in communities requires target population buy-in. Building on Tabak et $a l \mathrm{~s}^{28}$ argument that there is a limited local-level data source available to help decision makers "tailor policies that would most efficiently and effectively impact obesity rates", it is essential that local public health authorities assess and carefully consider public perception and receptivity to these policies/practices. Within this context, the present study provides insights into the utility of these PSEs and may help inform how best to tailor present and forthcoming obesity prevention initiatives in the community. 
Author affiliations

${ }^{1}$ Division of Chronic Disease and Injury Prevention, Los Angeles County Department of Public Health, Los Angeles, California, USA

${ }^{2}$ Department of Community Health Sciences, UCLA Fielding School of Public Health, Los Angeles, California, USA

${ }^{3}$ Department of Epidemiology, UCLA Fielding School of Public Health, Los Angeles, California, USA

${ }^{4}$ Department of Family Medicine, David Geffen School of Medicine at UCLA, Los Angeles, California, USA

Acknowledgements The authors thank the UCLA Institute for Digital Research and Education for technical assistance with the analysis. The authors also thank Amelia DeFosset and Lauren Gase from the Los Angeles County Department of Public Health and Jennie E. Brand from the UCLA Sociology Department for their technical support, and the Field Research Corporation for overseeing the original survey development and administration.

Contributors BR and TK conceptualized the initial analysis plan. BR supervised the data management, conducted the main analyses using the existing survey data, and led the drafting of the manuscript. TK contributed to the interpretation and presentation of the data, and provided critical revisions to the content of the manuscript.

Funding The authors received no financial support to conduct the present analysis.

Competing interests None declared.

Ethics approval The study received approval from the Institutional Review Board (IRB) at the Los Angeles County Department of Public Health.

Provenance and peer review Not commissioned; externally peer reviewed.

Data sharing statement No additional data are available.

Open Access This is an Open Access article distributed in accordance with the Creative Commons Attribution Non Commercial (CC BY-NC 4.0) license, which permits others to distribute, remix, adapt, build upon this work noncommercially, and license their derivative works on different terms, provided the original work is properly cited and the use is non-commercial. See: http:// creativecommons.org/licenses/by-nc/4.0/

\section{REFERENCES}

1. Brownell KD, Kersh R, Ludwig DS, et al. Personal responsibility and obesity: a constructive approach to a controversial issue. Health Aff (Millwood) 2010;29:379-87.

2. Glanz K, Basil M, Maibach E, et al. Why Americans eat what they do: taste, nutrition, cost, convenience, and weight control concerns as influences on food consumption. J Am Diet Assoc 1998;98:1118-26.

3. Rosenheck R. Fast food consumption and increased caloric intake: a systematic review of a trajectory towards weight gain and obesity risk. Obes Rev 2008;9:535-47.

4. Sacks G, Swinburn B, Lawrence M. Obesity Policy Action framework and analysis grids for a comprehensive policy approach to reducing obesity. Obes Rev 2009;10:76-86.

5. Huang TT, Drewnosksi A, Kumanyika S, et al. A systems-oriented multilevel framework for addressing obesity in the 21st century. Prev Chronic Dis 2009:6:A82.

6. Larson NI, Story MT, Nelson MC. Neighborhood Environments: disparities in access to healthy foods in the U.S. Am J Prev Med 2009;36:74-81.

7. Jago R, Baranowski T, Baranowski JC. Fruit and vegetable availability: a micro environmental mediating variable? Public Health Nutr 2007;10:681-9.

8. Kamphuis CB, Giskes K, de Bruijn GJ, et al. Environmental determinants of fruit and vegetable consumption among adults: a systematic review. Br J Nutr 2006;96:620-35.

9. Story M, Kaphingst KM, Robinson-O'Brien R, et al. Creating healthy food and eating environments: policy and environmental approaches. Annu Rev Public Health 2008;29:253-72.

10. McLeroy KR, Bibeau D, Steckler A, et al. An ecological perspective on health promotion programs. Health Educ Q 1988;15:351-77.
11. Robles B, Frost S, Moore L, et al. Overweight and obesity among ow-income women in rural West Virginia and urban Los Angeles County. Prev Med 2014;67:S34-9.

12. Robles $B$, Smith LV, Ponce $M$, et al. The influence of gender and self-efficacy on healthy eating in a low-income urban population affected by structural changes to the food environment. J Obes 2014;2014:908391.

13. Bunnell R, O'Neil D, Soler R, et al., Communities Putting Prevention to Work Program Group. Fifty communities putting prevention to work: accelerating chronic disease prevention through policy, systems and environmental change. J Community Health 2012;37:1081-90.

14. Los Angeles County Department of Public Health. Choose Health LA. Community Transformation Grant. http://publichealth.lacounty. gov/chronic/docs/CHLA_CTG_one_sheet_FINAL_8.5x11.pdf (accessed 20 Mar 2016).

15. Lyn R, Aytur S, Davis TA, et al. Policy, systems, and environmental approaches for obesity prevention: a framework to inform local and state action. J Public Health Manag Pract 2013;19(Suppl 1):S23-33.

16. Los Angeles County Department of Public Health, Office of Health Assessment and Epidemiology. Obesity and related mortality in Los Angeles County: a cities and communities health report. Los Angeles County Department of Public Health, 2011. http:// publichealth.lacounty.gov/ha/reports/habriefs/2007/obese_cities/ obesity_2011fs.PDF (accessed 5 Aug 2016).

17. Shih M, Dumke KA, Goran MI, et al. The association between community-level economic hardship and childhood obesity prevalence in Los Angeles. Pediatr Obes 2013;8:411-17.

18. Tomayko EJ, Flood TL, Tandias A, et al. Linking electronic health records with community-level data to understand childhood obesity risk. Pediatr Obes 2015;10:436-41.

19. Gabel JR, Whitmore H, Pickreign J, et al. Obesity and the workplace: current programs and attitudes among employers and employees. Health Aff (Millwood) 2009;28:46-56.

20. Evans WD, Finkelstein EA, Kamerow DB, et al. Public perceptions of childhood obesity. Am J Prev Med 2005;28:26-32.

21. Hilbert A, Rief W, Braehler E. What determines public support of obesity prevention? J Epidemiol Community Health 2007;61:585-90.

22. Suggs LS, McIntyre C. European Union public opinion on policy measures to address childhood overweight and obesity. J Public Health Policy 2011;32:91-103; discussion 104-6.

23. Lund TB, Sandøe P, Lassen J. Attitudes to publicly funded obesity treatment and prevention. Obesity (Silver Spring) 2011:19:1580-5.

24. Sikorski C, Luppa M, Schomerus G, et al. Public attitudes towards prevention of obesity. PLoS ONE 2012;7:e39325.

25. Beeken RJ, Wardle J. Public beliefs about the causes of obesity and attitudes towards policy initiatives in Great Britain. Public Health Nutr 2013;16:2132-7.

26. Barry CL, Brescoll VL, Brownell KD, et al. Obesity metaphors: how beliefs about the causes of obesity affect support for public policy. Milbank Q 2009;87:7-47.

27. Diepeveen S, Ling T, Suhrcke M, et al. Public acceptability of government intervention to change health-related behaviours: a systematic review and narrative synthesis. BMC Public Health 2013;13:756.

28. Tabak RG, Jones E, Jacobs JA, et al. Policy perceptions related to physical activity and healthy eating in Mississippi. $J$ Public Health Manag Pract 2013;19(Suppl 1):S97-104

29. Braveman $P$, Egerter S, Williams DR. The social determinants of health: coming of age. Annu Rev Public Health 2011;32:381-98.

30. DiCamillo M, Field M. The Field Poll Release \#2367: increasing concern among California Voters about childhood obesity: support for policies aimed at encouraging greater physical activity and healthier eating among children. Field Research Corporation, 2011. http://www.field.com/fieldpollonline/subscribers/Rls2367.pdf (accessed 5 Aug 2016)

31. DiCamillo M, Field M. The Field Poll Release \#2408: unhealthy eating, lack of physical activity seen as greatest health risk facing California kids. Voters Believe Obesity Prevention Efforts should involve the Community as well as kids and their families. Field Research Corporation, 2012. http://www.field.com/fieldpollonline/ subscribers/Rls2408.pdf (accessed 5 Aug 2016).

32. DiCamillo M, Field M. The Field Poll Release \#2436: Most Californians See a direct linkage between obesity and sugary sodas. Two in three voters support taxing sugar-sweetened beverages if proceeds are tied to improving school nutrition and physical activity programs. Field Research Corporation, 2013. http://www.field.com/ fieldpollonline/subscribers/RIs2436.pdf (accessed 5 Aug 2016).

33. The California Endowment. 2010 Field-TCE Childhood Obesity Prevention Survey. Internal report by Internal Field Research Corporation conducted on behalf of The California Endowment. 2010. 
34. Los Angeles County Department of Public Health, Office of Health Assessment and Epidemiology. Life expectancy in Los Angeles County: How long do we live and why? A communities and city report. Los Angeles County, Department of Public Health, 2010. http://www.publichealth.lacounty.gov/epi/docs/Life\%20Expectancy\% 20Final_web.pdf (accessed 5 Aug 2016).

35. Yaeger JP, Temte JL, Hanrahan LP, et al. Roles of clinician, patient, and community characteristics in the management of pediatric upper respiratory tract infections. Ann Fam Med 2015;13:529-36.

36. McHorney CA, Ware JE Jr, Lu JF, et al. The MOS 36-item Short-Form Health Survey (SF-36): III. Tests of data quality, scaling assumptions, and reliability across diverse patient groups. Med Care 1994;32:40-66.

37. Centers for Disease Control and Prevention. 2007 NHANES Weigh History-WHQ. https://www.cdc.gov/nchs/data/nhanes/nhanes_07_ 08/whq07_08_eng.pdf (accessed 5 Aug 2016).

38. Field Research Corporation. A summary of the methods used to conduct a survey of Los Angeles County registered voters about food policy and healthy eating. Internal survey methodology report conducted by Field Research Corporation, October 2013

39. Acock AC. Working with missing values. J Marriage Fam 2005;67:1741-3737.
40. Dalen JE, Waterbrook K, Alpert JS. Why do so many Americans oppose the Affordable Care Act? Am J Med 2015;128: 807-10.

41. Margalit Y. Explaining social policy preferences: evidence from the Great Recession. Am Pol Sci Rev 2013;107:80-103.

42. Gollust SE, Lantz PM, Ubel PA. The polarizing effect of news media messages about the social determinants of health. Am J Public Health 2009;99:2160-7.

43. Health literacy: report of the Council on Scientific Affairs. Ad Hoc Committee on Health Literacy for the Council of Scientific Affairs, American Medical Association. JAMA 1999;281:552-7.

44. Wang Y, Beydoun MA. The obesity epidemic in the United Statesgender, age, socioeconomic racial/ethnic, and geographic characteristics: a systematic review and meta-regression analysis. Epidemiol Rev 2007:29:6-28. Epub ahead of print: 17 May 2017.

45. Mensah GA, Mokdad AH, Ford ES, et al. State of disparities in cardiovascular health in the United States. Circulation 2005;111:1233-41.

46. Black JL, Macinko J. Neighborhoods and obesity. Nutr Rev 2008;66:2-20.

47. Link MW, Battaglia MP, Frankel MR, et al. A comparison of address-based sampling (ABS) versus random-digit dialing (RDD) for general population surveys. Public Opin Q 2008;71:6-27. 